\title{
Distribución y abundancia de larvas de langostino colorado Pleuroncodes monodon frente a la costa de Concepción, Chile
}

\author{
SERGIO PALMA G. \\ Escuela de Ciencias del Mar \\ Universidad Católica de Valparaíso \\ Casilla 1020, Valparaíso, Chile
}

RESUMEN. Se analiza la distribución y abundancia de larvas de langostino colorado Pleuroncodes monodon capturadas en cuatro cruceros oceanográficos efectuados entre abril y diciembre de 1991, frente a la costa de Concepción, Chile. Las muestras de zooplancton se obtuvieron en 15 estaciones oceanográficas, mediante pescas oblicuas con redes Bongo desde el fondo a superficie, con un máximo de $200 \mathrm{~m}$ de profundidad.

En todos los cruceros realizados se observó la presencia de larvas de langostino, encontrándose la mayor abundancia en noviembre. Las mayores densidades de larvas se detectaron en aguas sobre la plataforma continental, particularmente en el norte del área de estudio. La biomasa zooplanctónica alcanzó valores máximos en abril y mínimos en junio, registrándose las mayores densidades en aguas de la plataforma, en el norte y sur del área de estudio.

La distribución temporal de los distintos estados de desarrollo (zoeas y postlarvas), sugiere el desplazamiento desde la costa hacia el talud, a medida que avanza la metamorfosis larval. La distribución vertical de las larvas mostró una preferencia de los estados de zoea por el estrato 0-25 m, mientras que las postlarvas se concentraron en el estrato 25-50 $\mathrm{m}$. Bajo $50 \mathrm{~m}$ de profundidad, se observó una escasa cantidad de individuos.

Palabras claves: Pleuroncodes monodon, larvas langostino colorado, biomasa zooplancton, distribución espacio-temporal, abundancia.

\section{Distribution and abundance ofred shrimp larvae Pleuroncodes monodon off the Concepcion coast, Chile}

\begin{abstract}
The distribution and abundance of red shrimp larvae Pleuroncodes monodon catched during four oceanographic cruises conducted between april and december 1991, off the coast of Concepcion, Chile, are described. Zooplankton was sampled at 15 oceanographic stations. Oblique sampling was done with Bongo nets from bottom to surface from a maximum of $200 \mathrm{~m}$ depth.

Shrimp larvae were present in samples from all cruises, and were most numerous in november. The greatest concentrations of larvae were detected in waters over the continental shelf, particulary to the north of the area of study. The zooplanktonic biomass showed maximum values in april and minimum values in june, with highest densities in waters over the shelf but towards north and south of the area of study.

The time distribution of the different development stages (zoeae through postlarvae), suggests a displacement from the coast towards the slope, as the larvae develops. The vertical distribution of larvae indicates the preference of zoea stages for the 0-25 m stratum, while the postlarvae concentrate within the $25-50 \mathrm{~m}$ stratum. Below $50 \mathrm{~m}$ depth, there is a strong decrease in the number of indivuals.
\end{abstract}

Key words: Pleuroncodes monodon, red shrimp larvae, zooplankton biomass, temporal and spatial distribution, abundance. 


\section{INTRODUCCION}

En aguas frente a la costa chilena, se ha registrado la presencia de dieciséis especies de crustáceos decápodos de la familia Galatheidae. Según Retamal (1981), de éstas solamente cuatro coexisten en aguas de la zona de Concepción: Galathea lenzi Rathbun; Pleuroncodes monodon Milne Edwards; Cervimunida johni Porter y Munidopsis aspera Henderson. Por la abundancia de estos recursos bentodemersales, sólo el langostino colorado Pleuroncodes monodon y el langostino amarillo Cervimunida johni, han sido explotados comercialmente en aguas de la zona.

El área de distribución del langostino colorado se extiende desde la Isla Lobos de Afuera, Perú, hasta Ancud, Chile (Haig, 1955), mientras que su área de pesca está localizada en la zona comprendida entre Coquimbo $\left(30^{\circ} \mathrm{S}\right)$ y Talcahuano $\left(37^{\circ} \mathrm{S}\right)$. El ciclo vital de esta especie comprende fases larvarias de distribución planctónica y fases juveniles y adultas, que habitan los fondos blandos de la plataforma y borde continental.

Frente a la costa de Concepción, el langostino colorado vive entre los 50 y $350 \mathrm{~m}$ de profundidad (Palma y Arana, 1990). Por su rango de distribución batimétrica, se evidencia que se encuentra bajo la influencia del agua subantártica que cubre la plataforma continental en otoño e invierno, y por el agua ecuatorial subsuperficial que asciende hasta áreas más someras en primavera y verano, durante los procesos de surgencia (Gallardo et al., 1993). Según Bahamonde et al. (1986), la abundancia y distribución de esta especie estaría afectada por la dinámica del agua ecuatorial subsuperficial, de alta salinidad y bajo contenido de oxígeno disuelto.

Se ha observado que el rango de distribución batimétrica del langostino, varía en función de su comportamiento reproductivo (Bustos et al., 1982; Palma y Arana, 1990). Es así como, en otoño cuando se inicia el período de portación de huevos, las hembras se encuentran a mayor profundidad en fondos de 200 a 350 m; en cambio a fines de invierno, período en que se registra el mayor porcentaje de hembras ovíferas, se detecta la migración de los individuos hacia aguas más someras comprendidas entre 70 y 200 m de profundidad (Palma y Arana, 1990).

Frente a la costa de Concepción, el ciclo reproductivo de esta especie se extiende durante casi todo el año, encontrándose hembras ovíferas desde febrero hasta diciembre. Sin embargo, el período de mayor intensidad de portación se ubica entre comienzos de mayo y fines de octubre (Palma y Arana, 1990).

La vida planctónica del langostino colorado comprende cinco estados larvales de zoea y uno de postlarva (Fagetti y Campodónico, 1971; Bustos et al., 1982). Una vez que los individuos han alcanzado el estado de postlarva, comienzan su desplazamiento hacia la zona bentónica donde ocurre el reclutamiento.

En la zona centro-sur del país, el langostino colorado es un componente esencial de la alimentación de varios peces bentodemersales de importancia económica (merluza Merluccius gayi, congrio dorado Genypterus blacodes, congrio negro Genypterus maculatus y lenguado de ojos grandes Hippoglossina macrops); y de otras especies de su fauna acompañante (peje rata Coelorhynchus aconcagua, tiburón Centroscyllium granulosum, y las rayas Raja chilensis y Bathyraja sp.) (Henríquez y Bahamonde, 1964; Retamal, 1977; Bahamonde y Zavala, 1981; Arancibia y Meléndez, 1987).

Debido a la intensa explotación pesquera soportada por este recurso en la década de los setenta, a partir de 1979 la Subsecretaría de Pesca, dictó medidas de manejo destinadas a regular la actividad extractiva del langostino colorado. En la actualidad, la pesquería de este crustáceo está declarada en estado de plena explotación y está sujeta a régimen de pesquería en recuperación, efectuándose las capturas en una pequeña área ubicada frente a la costa de la VIII Región (35³0'-3650’S).

Como es de esperar, la actividad extractiva no sólo influye directamente sobre la biomasa del recurso, sino también sobre el aporte de nuevas crías a la población. Por lo tanto, además de conocer el ciclo reproductivo del langostino, es necesario determinar la época del año en que aparecen las larvas en el plancton, así como sus fluctuaciones espacio-temporales.

Este trabajo, forma parte del Programa «Estudio de la dinámica de los focos de abundancia del langostino colorado (Pleuroncodes monodon) frente a la región del Bío-Bío», financiado por la Compañía Pesquera Camanchaca S.A. que comprende una serie de investigaciones multidisciplinarias, destinadas a aportar nuevos antecedentes sobre la biología, ecología y pesquería de esta especie, para mejorar 
las medidas de manejo y asegurar la sustentabilidad de su explotación en el tiempo.

\section{MATERIALES Y METODOS}

En el período comprendido entre abril y diciembre de 1991, se efectuaron cuatro cruceros destinados a conocer la distribución de la biomasa zooplanctónica y de las larvas de langostino colorado frente a la costa

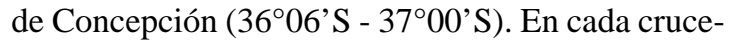
ro se efectuaron 15 estaciones oceanográficas, distribuidas en tres secciones perpendiculares a la costa (Fig. 1).

Estos cruceros se efectuaron con los buques de arrastre por popa PAM «Rigel» y PAM «Antares» de la Compañía Pesquera Camanchaca S.A., en las siguientes épocas del año:

Crucero de otoño : 4 al 11 de abril

Crucero de invierno : 24 al 29 de junio

Crucero de mediados de primavera : 2 al 5 de noviembre

Crucero de fines de primavera : 10 al 13 de diciembre
El muestreo de zooplancton se efectuó mediante pescas oblicuas dobles realizadas entre la superficie y el fondo, con una profundidad máxima de 200 metros. Para las recolectas de plancton se utilizó una red Bongo de $60 \mathrm{~cm}$ de diámetro y 335 micras de mallas, provista de flujómetros TSK para la estimación del volumen de agua filtrada. Las muestras de plancton fueron preservadas para su análisis en laboratorio, en una solución de agua de mar con formalina al $5 \%$ neutralizada con tetraborato de sodio.

La biomasa zooplanctónica se determinó midiendo el desplazamiento de volumen de plancton, previa remoción de los organismos gelatinosos de mayor tamaño corporal, y se expresó como volumen de plancton húmedo en $\mathrm{ml} / 1000 \mathrm{~m}^{3}$ de agua de mar.

La distribución espacio-temporal de las larvas de langostino se expresó en número de ind./1000 $\mathrm{m}^{3} \mathrm{de}$ agua de mar. La representación gráfica de la abundancia de larvas se realizó en base a una escala métrica $\log ^{2}$, que permite determinar clases de abundancia con valores equidistantes (Frontier, 1980). Porpérdida del sistema de redes Bongo, no se obtuvieron muestras en las estaciones 6 y 3 de los cruceros efectuados en abril y diciembre respectivamente.

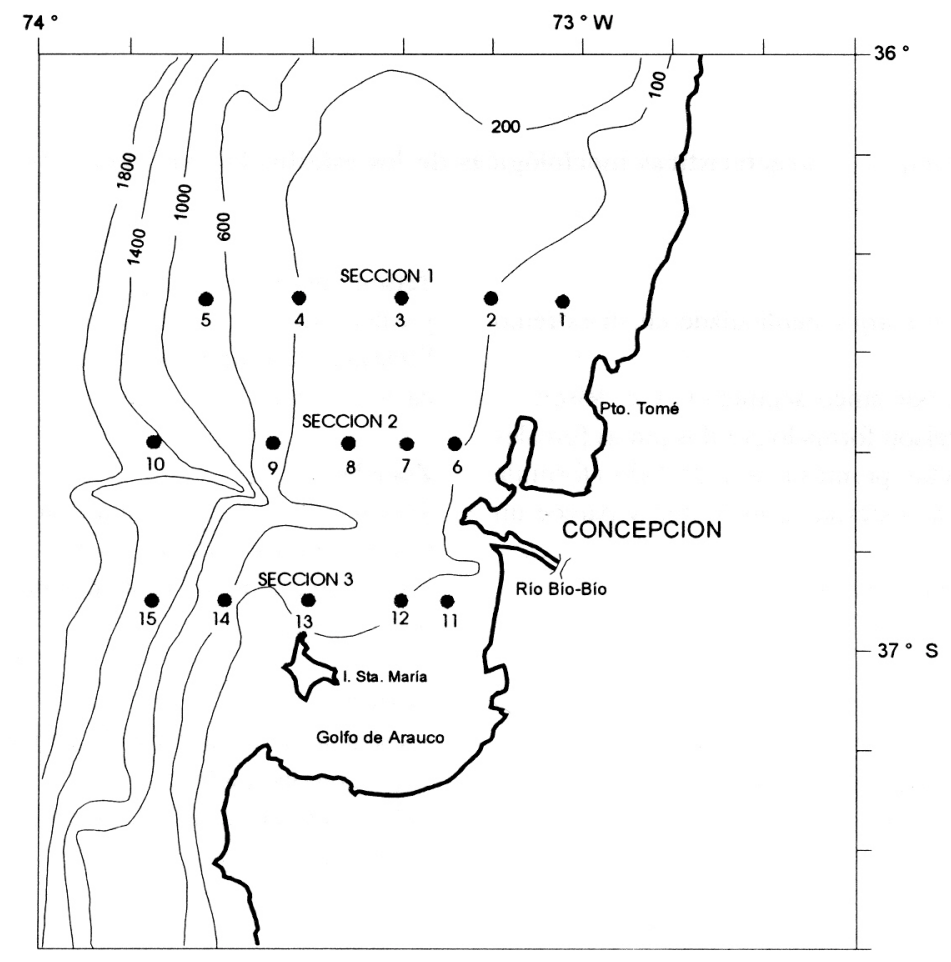

Figura 1. Estaciones oceanográficas en el área estudiada. 
Además, en las estaciones más costeras de los dos cruceros de primavera (estaciones 1 a 3), se efectuaron arrastres verticales estratificados de plancton con redes WP-2 de $57 \mathrm{~cm}$ de diámetro y 335 micras de mallas. De acuerdo con la profundidad de la columna de agua, en la estación 1 se tomaron muestras en los estratos de 0-25 y 25-50 m, mientras que en las estaciones 2 y 3 se muestrearon los estratos de 0-50 y 50-100 $\mathrm{m}$ de profundidad.

Con las muestras estratificadas se determinó la distribución vertical de las larvas de langostino, basándose en el número de ind./1000 $\mathrm{m}^{3}$ de agua de mar filtrada y se expresó en porcentaje de individuos por estrato.

En el laboratorio se separaron e identificaron los distintos estados de desarrollo, utilizando las descripciones para Pleuroncodes monodon (Fagetti y Campodónico, 1971; Bustos et al., 1982; Mujica y Bahamonde, 1990), y Cervimunida johni (Fagetti, 1960). Con estos antecedentes, se elaboró la Tabla 1 que contiene las características morfológicas más importantes de cada estado de desarrollo.

Finalmente, para determinar el grado de asociación entre los distintos estados larvales del langostino colorado, se utilizó el índice de similitud biocenótica de Winer «W» (Sáiz, 1980).

$$
\mathrm{W}=\frac{\sum \mathrm{xy}}{\sqrt{\left(\sum \mathrm{x}^{2} \sum \mathrm{y}^{2}\right)}}
$$

donde:

$\mathbf{x}$ e $\mathbf{y}=$ es el número de individuos de cada estado de desarrollo en $1000 \mathrm{~m}^{3}$ de agua de mar, en las muestras A y B respectivamente.

\section{RESULTADOS}

\section{Distribución temporal de la biomasa zooplanctónica}

La biomasa zooplanctónica, expresada como volumen húmedo de plancton, fluctuó entre un mínimo de $36 \mathrm{ml} / 1000 \mathrm{~m}^{3}$ en junio en la estación 4 , y un máximo de $6.293 \mathrm{ml} / 1000 \mathrm{~m}^{3}$ en abril en la estación 11 .

Los valores medios de biomasa experimentaron variaciones muy marcadas en los distintos meses del año (Tabla 2). La mayor fluctuación se observó entre abril y junio, cuando el valor medio de biomasa disminuyó en más de once veces. En primavera, noviembre y diciembre, se detectó una recuperación de los valores de biomasa zooplanctónica respecto a los obtenidos en junio.

\section{Tabla 1. Principales características morfológicas de los estados larvales del langostino colorado}

Zoea I:

Caparazón con un rostro largo, denticulado en su extremo distal.

Abdomen constituido por cinco segmentos y el telson. Margen posterior del telson formado por dos ramas furcales denticuladas y seis setas plumosas a cada lado (fórmula $6+6$ ); la primera o más externa es muy fina y parece un pelo.

Tercer maxilípedo rudimentario.

No hay pleópodos ni urópodos.

\section{Zoea II:}

Rostro con denticulaciones en toda su extensión. Telson con siete setas plumosas a cada lado (fórmula 7+7). Tercer maxilípedo funcional y con setas.

\section{Zoea III:}

Abdomen con un sexto segmento, provisto de una espina media dorsal.
Telson con ocho setas plumosas a cada lado, tres externas y cinco internas (fórmula $8+8$ ).

Presencia de urópodos. La rama interna es poco desarrollada y $\sin$ setas.

\section{Zoea IV:}

Telson con nueve setas plumosas a cada lado, tres externas y seis internas (fórmula 9+9).

Rama interna de los urópodos bien desarrollada y con numerosas setas.

\section{Zoea V:}

Presencia de cinco pares de periópodos bajo el caparazón, el primero es quelado

Telson con diez setas plumosas a cada lado, tres externas y siete internas (fórmula $10+10$ ).

Urópodos bien desarrollados y con numerosas setas. Cuatro pares de pleópodos birramosos desde el segundo a quinto segmento del abdomen. 
Tabla 2. Biomasa zooplanctónica expresada como plancton húmedo en $\mathrm{ml} / 1000 \mathrm{~m}^{3}$.

\begin{tabular}{lrrrr}
\hline & Abr & Jun & Nov & Dic \\
\hline Biomasa mínima & 97 & 36 & 113 & 204 \\
Biomasa máxima & 6.293 & 344 & 1.653 & 938 \\
Biomasa media & 1.560 & 136 & 484 & 507 \\
Desv. estándar & 1.644 & 96 & 400 & 264 \\
$\mathrm{~N}^{\circ}$ estaciones & 14 & 15 & 15 & 14 \\
\hline
\end{tabular}

Las mayores variaciones en la distribución temporal de la biomasa zooplanctónica se debieron a cambios importantes en la abundancia de copépodos y eufáusidos que predominaron durante todos los períodos del año en el área de estudio.

En otoño se obtuvieron los valores más elevados del año, especialmente en las estaciones más costeras de las secciones norte y sur, registrándose un máximo de $6.293 \mathrm{ml} / 1000 \mathrm{~m}^{3}$ en la estación II (Fig. 2). En invierno, se registró un brusco descenso de la biomasa en toda el área, que se tradujo en valores medios de $136 \mathrm{ml} / 1000 \mathrm{~m}^{3}$. Solamente en las estaciones 3 y 11, se determinaron valores superiores a $300 \mathrm{ml} / 1000 \mathrm{~m}^{3}$.

En primavera, noviembre y diciembre, se registró un marcado incremento de la biomasa en toda el área de estudio, especialmente en la zona nerítica. Este incremento fue aproximadamente tres a cuatro veces superior a los promedios invernales. En noviembre los valores más altos se obtuvieron en las estaciones 4 y 11 , con 1.653 y $1.074 \mathrm{ml} / 1000 \mathrm{~m}^{3}$ respectivamente, mientras que en diciembre las mayores abundancias se registraron en la sección sur, con un máximo de $938 \mathrm{ml} / 1000 \mathrm{~m}^{3}$ en la estación 15 .

En general, independientemente de la época del año, se observó que los mayores volúmenes de plancton se obtuvieron en aguas de la plataforma continental, particularmente en las secciones norte y sur del área de estudio. Esto indica que al norte de la
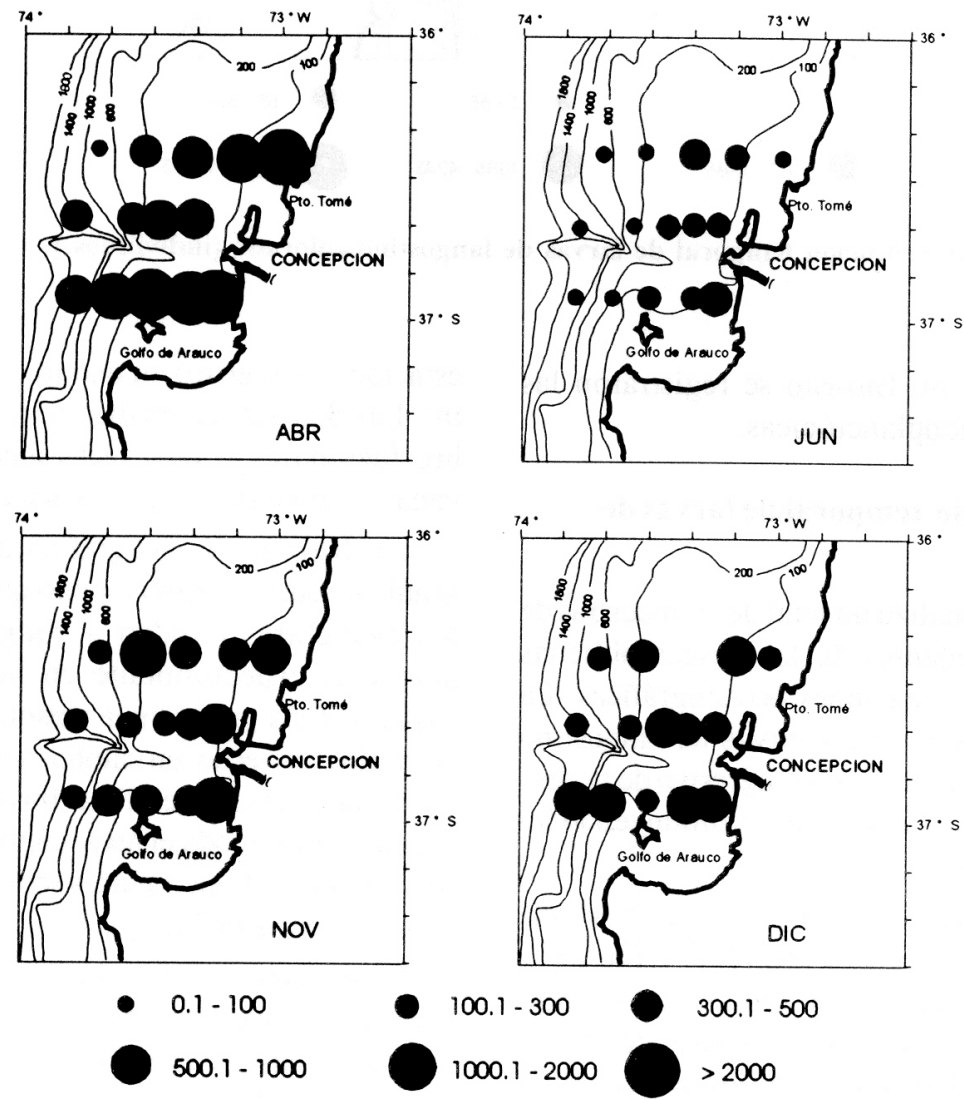

Figura 2. Distribución temporal de la biomasa zooplanctónica (ml de plancton húmedo por 1000 m³ $^{3}$. 

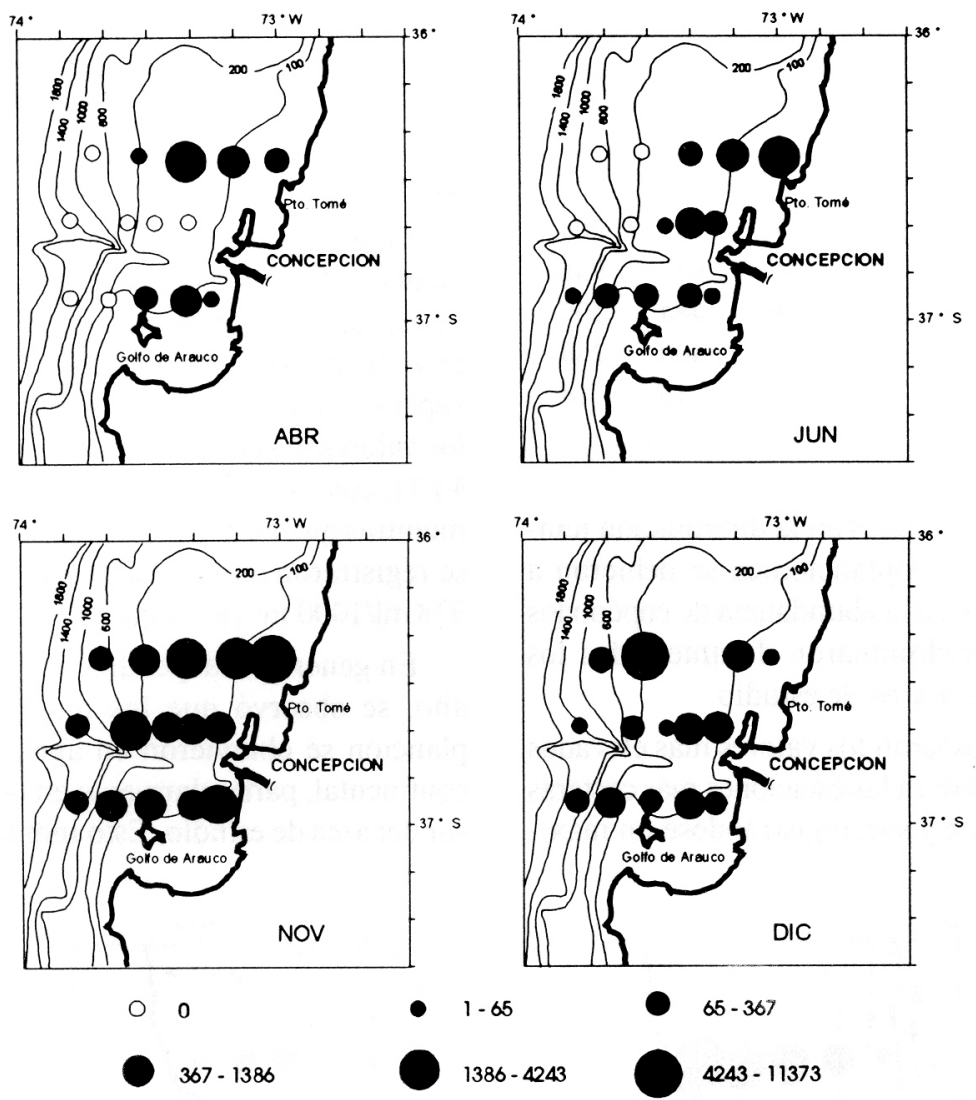

Figura 3. Distribución temporal de larvas de langostino colorado (individuos por $1000 \mathrm{~m}^{3}$ ).

desembocadura del río Bío-Bío se registraron las menores biomasas zooplanctónicas.

\section{Distribución espacio-temporal de larvas de langostino}

En cada crucero se analizó un total de 30 muestras de zooplancton, procedentes de las pescas oblicuas obtenidas en las 15 estaciones oceanográficas. La distribución estacional de las larvas de langostino colorado mostró un incremento progresivo de la densidad larval de abril a noviembre, disminuyendo levemente en diciembre (Fig. 3).

Durante el período de estudio, se determinó una densidad media con valores de 293, 447, 1.576 y 871 ind./1000 $\mathrm{m}^{3}$, en los cruceros de abril, junio, noviembre y diciembre respectivamente. Las mayores densidades relativas se observaron en noviembre, en la zona costera de la sección norte. Es así como en la estación 1 se registró un máximo de 8.691 ind./1000 $\mathrm{m}^{3}$. Las densidades medias registradas en noviembre, fueron tres a cinco veces superiores a las observadas en invierno y otoño respectivamente.

La distribución geográfica de las larvas en el gradiente costa-océano mostró que, a través del año, los ejemplares tienden a congregarse en aguas neríticas, especialmente en las estaciones más costeras. Esta preferencia costera fue más marcada en otoño e invierno, en cambio a mediados de primavera, las larvas se distribuyeron más homogéneamente en toda el área, capturándose un número importante de ejemplares sobre el borde de la plataforma continental (Fig. 3).

En relación a su distribución latitudinal, las mayores densidades de organismos se recolectaron en la sección norte de la zona de estudio. Esta abundancia fue muy superior a la sumatoria de las densidades estimadas para las secciones central y sur (Fig. 4). 


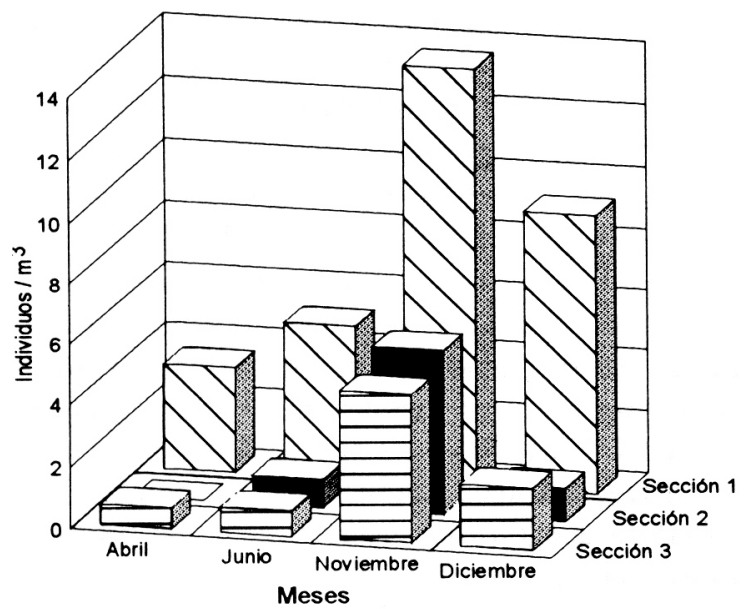

Figura 4. Distribución de larvas de langostino colorado en las distintas secciones oceanográficas.

\section{Distribución espacio-temporal de los distintos} estados de desarrollo

La distribución espacio-temporal de los distintos estados larvales del langostino colorado, presentó variaciones importantes, que indudablemente, están relacionadas con el desarrollo y avance del ciclo reproductivo de esta especie.

\section{Distribución de larvas en estado de zoea 1}

En abril no se encontraron larvas en estado I en el plancton (Fig. 5). En junio se recolectaron las primeras larvas en algunas estaciones de la zona nerítica, encontrándose un máximo de 2.455 ind./1000 m³ en la estación más costera de la sección norte.

En noviembre se registró la presencia de ejemplares en todas las estaciones oceanográficas. Las mayores densidades se obtuvieron en aguas costeras de la sección norte (estación 1) y al borde del talud en la sección central (estación 9), donde se determinó un máximo de 2.430 ind./1000 $\mathrm{m}^{3}$. En diciembre
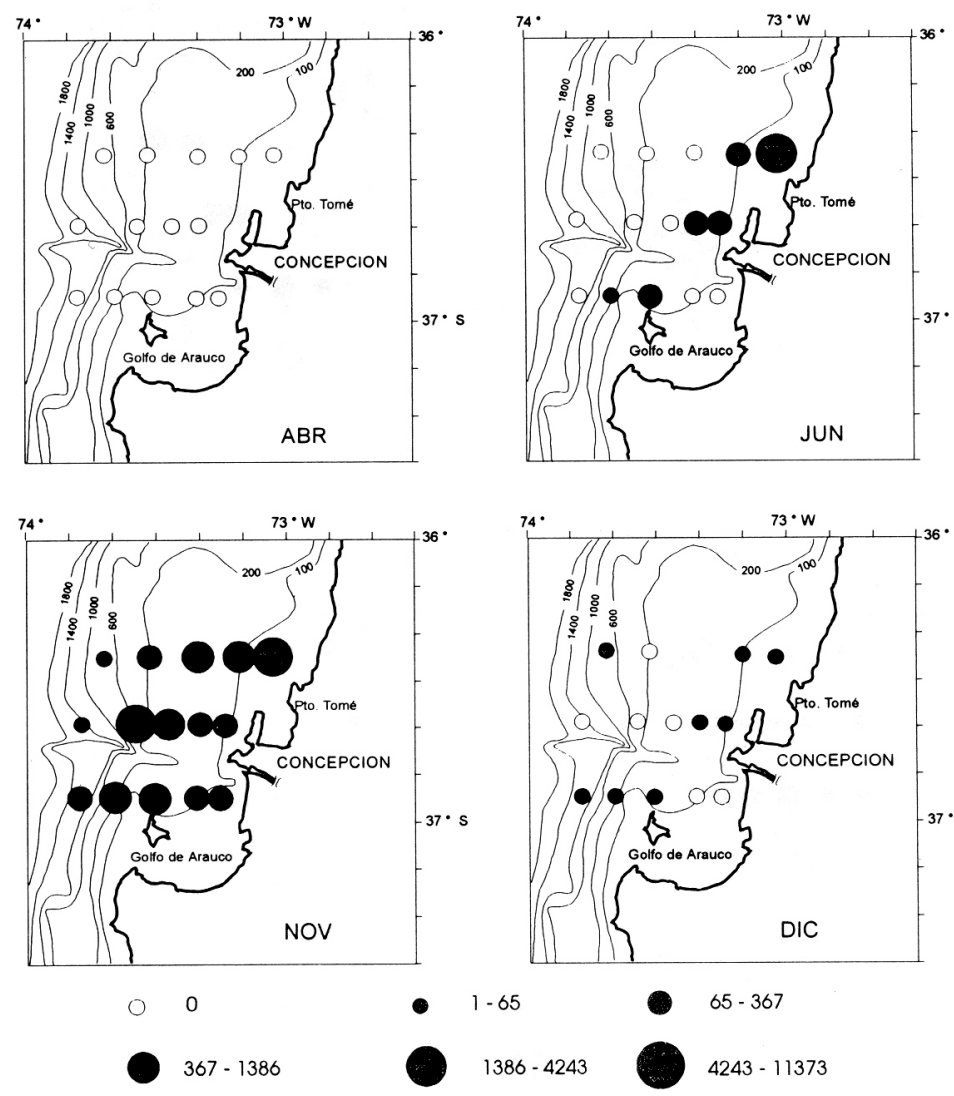

$65-367$
$1386-4243 \bigcirc$
$4243-11373$

Figura 5. Distribución de larvas de langostino colorado en estado I (individuos por $1000 \mathbf{m}^{3}$ ). 
se detectó un brusco descenso en la cantidad de larvas y una presencia irregular en el área de muestreo, obteniéndose un máximo de 40 ind./ $1000 \mathrm{~m}^{3}$ en la estación 6 (Fig. 5).

Distribución de larvas en estado de zoea II En este estado, las larvas presentaron una distribución espacio-temporal semejante al estado precedente, no encontrándose larvas en abril (Fig. 6). En el crucero de junio aparecieron ejemplares en las estaciones más costeras, registrándose un máximo de 895 ind./1000 $\mathrm{m}^{3}$ en la estación 1 .

En noviembre se detectó el periodo de mayor abundancia y cobertura geográfica, estimándose una densidad máxima de 2.336 ind./1000 $\mathrm{m}^{3}$ en la estación 1. Al igual que el estado anterior, su presencia en el plancton disminuyó a fines de primavera, encontrándose en diciembre una mayor cantidad de ejemplare_s en las estaciones de la sección sur. En este período, la mayor concentración de 259 ind./1000 $\mathrm{m}^{3}$ se registró en la estación 2 (Fig. 6).
Distribución de larvas en estado de zoea 111 Las larvas en estado III también se encontraron en el plancton a partir de junio, presentando una distribución geográfica coincidente con aquélla de los estados precedentes (Fig. 7). En este período, se recolectaron larvas en la mayor parte de las estaciones neriticas, registrándose las mayores concentraciones en la zona costera de la sección norte, con un máximo de 301 ind./1000 $\mathrm{m}^{3}$ en la estación 2.

Al igual que en el caso de los estados anteriores, el período de mayor abundancia y cobertura geográfica se observó en noviembre, determinándose densidades máximas en aguas neríticas. El valor máximo fue de 1.733 ind./1000 $\mathrm{m}^{3}$ en la estación 1 . En diciembre se registró una disminución en su abundancia y cobertura geográfica, particularmente en las estaciones más costeras, con un máximo relativo de 226 ind./ $1000 \mathrm{~m}^{3}$ en la estación 2 (F ig. 7).

Distribución de larvas en estado de zoea IV

Las larvas en estado IV también se recolectaron a partir
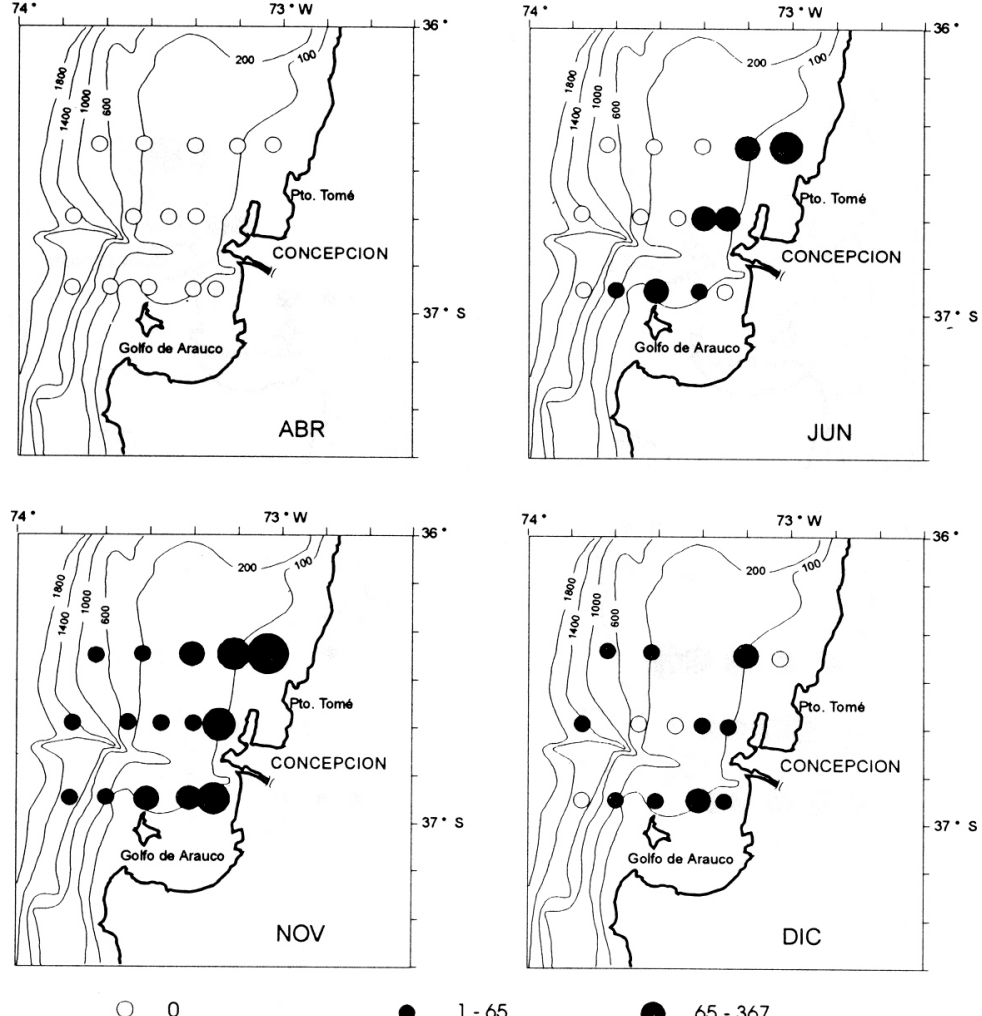

00

$367-1386$

$1-65$

$65-367$

$1386-4243$

Figura 6. Distribución de larvas de langostino colorado en estado II (individuos por $1000 \mathbf{~ m}^{3}$ ). 
del crucero de junio, aunque presentaron una mayor cobertura geográfica que los estados precedentes, especialmente en la sección sur. La mayor abundancia se determinó en la estación 2, donde se capturaron 544 ind./1000 $\mathrm{m}^{3}$ (Fig. 8).

En noviembre se detectó la mayor abundancia y cobertura geográfica, con un máximo de 1.877 ind./1000 $\mathrm{m}^{3}$ en la estación 1 . En diciembre se registró un descenso del número de individuos en aguas costeras, observándose una mayor cantidad de organismos sobre el borde del talud de las secciones norte y sur, con una densidad máxima de 525 ind./1000 $\mathrm{m}^{3}$ en la estación 4 (Fig. 8).

\section{Distribución de larvas en estado de zoea $\mathrm{V}$}

En general, las larvas en estado $\mathrm{V}$ fueron más escasas que las de los estados precedentes. A diferencia de los estados anteriores, las larvas en estado $\mathrm{V}$ se encontraron en el plancton a partir de abril, distribuyéndose únicamente en aguas costeras de la sección norte, donde alcanzaron una densidad máxima de 52 ind./1000 $\mathrm{m}^{3}$ en la estación 1 . En junio sólo se capturaron algunos especímenes en la estación 2 (Fig. 9).

En noviembre se determinaron las mayores densidades de individuos, especialmente en la sección norte, con un máximo de 215 ind./1000 $\mathrm{m}^{3}$ en la estación 3. En diciembre se registró una disminución en su abundancia y cobertura geográfica, detectándose dos áreas de mayor densidad al borde del talud (Fig. 9).

\section{Distribución de postlarvas}

Finalmente, el último estado de desarrollo larvario, correspondiente a la postlarva, presentó una distribución muy distinta a la observada en los estados I a V (Fig. 10). En efecto, en abril se observó un número importante de ejemplares en aguas costeras de las secciones norte y sur, registrándose un máximo de 2.067 ind./1000 $\mathrm{m}^{3}$ en la estación 3. En cambio en junio, no se encontraron postlarvas en el plancton de la zona.

En noviembre se recolectaron especímenes en
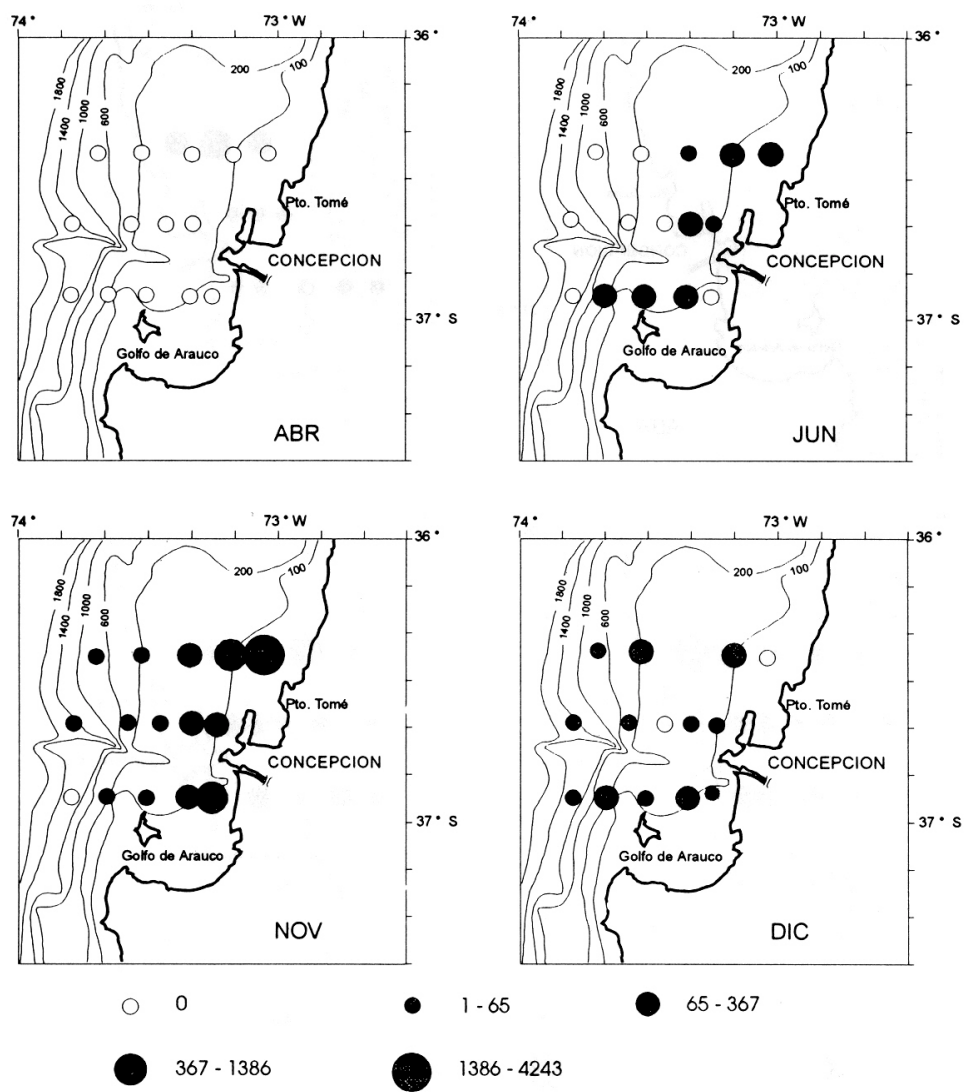

$386-4243$

Figura 7. Distribución de larvas de langostino colorado en estado III (individuos por $1000 \mathbf{~ m}^{3}$ ). 
todas las estaciones oceanográficas, con una mayor abundancia en la sección norte. La mayor densidad de organismos fue de 230 ind./1000 $\mathrm{m}^{3}$ y se registró en la estación 14. A diferencia de los estados de zoea, en diciembre se registró la mayor abundancia estacional, capturándose un máximo de 7.562 ind./ $1000 \mathrm{~m}^{3}$ en la estación 4 (Fig. 10).

\section{Asociación entre los distintos estados de desarrollo}

Para determinar el grado de asociación entre los distintos estados larvales del langostino colorado capturados en cada período del año, se estimó el índice de similitud de Winer, encontrándose diferencias importantes en función del tiempo (Fig. 11).

En abril la presencia exclusiva de los últimos estados de desarrollo, zoea $\mathrm{V}$ y postlarva, mostró un grado mínimo de asociación entre ambos estados. Debido a que las zoeas $\mathrm{V}$ estuvieron restringidas a las dos estaciones costeras de la sección norte, mientras que las postlarvas tuvieron una mayor abundan- cia y cobertura geográfica en las secciones norte y sur del área de estudio.

En junio, se observó una relación más estrecha entre los estados consecutivos, detectándose una asociación superior al $80 \%$, tanto entre las zoeas I y II como entre las zoeas III y IV Los estados I y 11 tuvieron una distribución más costera que los estados III y IV.

A mediados de primavera, en noviembre, se registró una estrecha asociación en la distribución de los estados larvales consecutivos, reflejando así la secuencia que se establece entre los distintos estados larvales a medida que los organismos van completando su metamorfosis. El alto índice de similitud obtenido en este período (> 60\%), es el resultado de la participación masiva de hembras oviferas en el proceso de liberación larvaria señalada por Palma y Arana (1990).

A fines de primavera, en diciembre, se detectaron dos grupos de estados de desarrollo: uno constituido por los estados I a III, y otro por los estados IV a
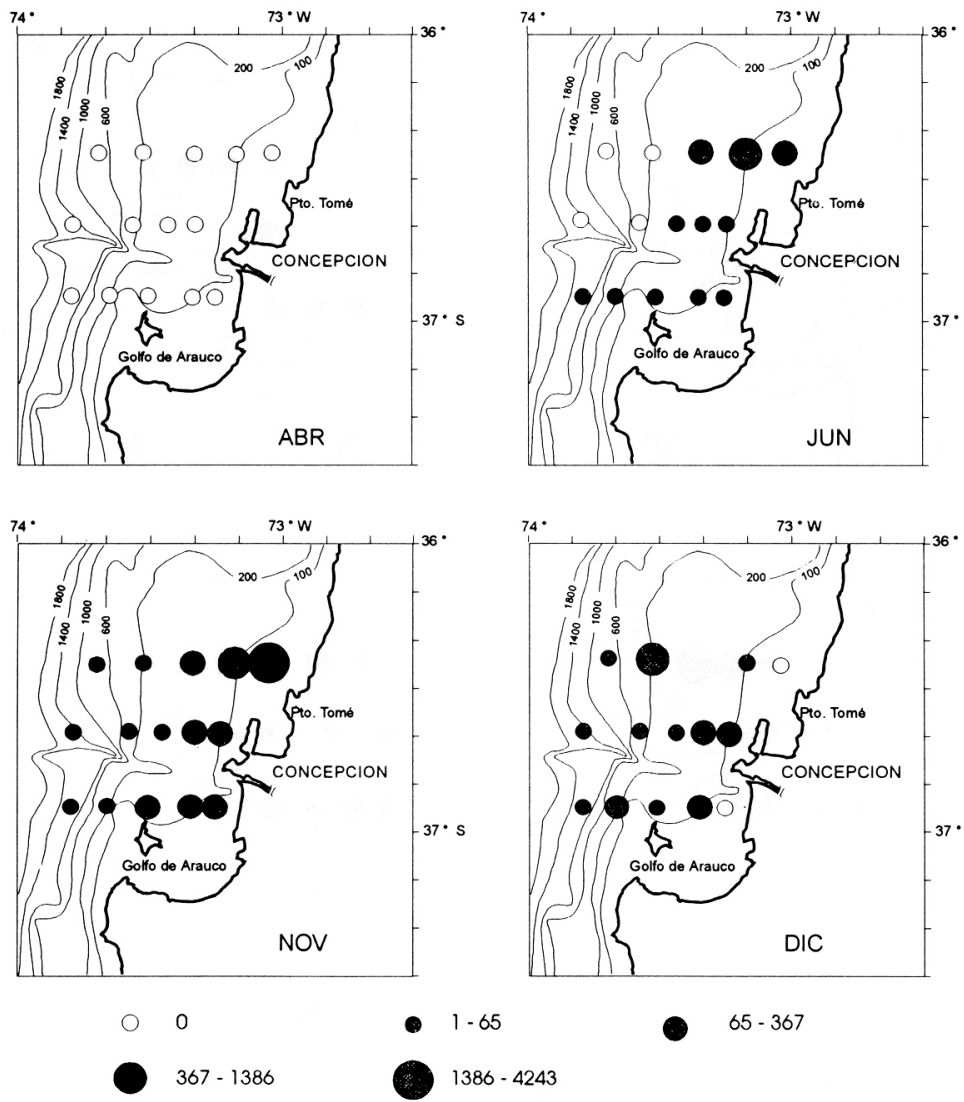

$65-367$

$$
367-1386 \text { 1386-4243 }
$$

Figura 8. Distribución de larvas de langostino colorado en estado IV (individuos por $1000 \mathbf{~ m}^{3}$ ). 
VI (Fig. 11). El bajo valor de similitud entre estos dos grupos $(32 \%)$, indicaria que el primero está formado por larvas liberadas por las últimas hembras ovíferas de la temporada. mientras que el segundo estaría compuesto por especímenes que están terminando su desarrollo larvario.

\section{Distribución vertical de larvas de langostino}

La cantidad de larvas capturadas en los estratos verticales de las estaciones costeras a mediados de primavera (noviembre) y fines de primavera (diciembre), fue bastante escasa. En noviembre se capturaron 293 ejemplares (94\% en la columna de agua de 0-50 m y 6\% entre 50-100 $\mathrm{m}$ de profundidad), mientras que en diciembre, sólo se capturaron 48 ejemplares ( $85 \%$ en la columna de $0-50 \mathrm{~m}$ y $15 \%$ entre 50-100 m).

De acuerdo con estos resultados, se puede observar que en ambos cruceros, el mayor porcentaje de larvas se encontró en las capas superiores de la columna de agua, en el estrato de 0-25 m en la esta-
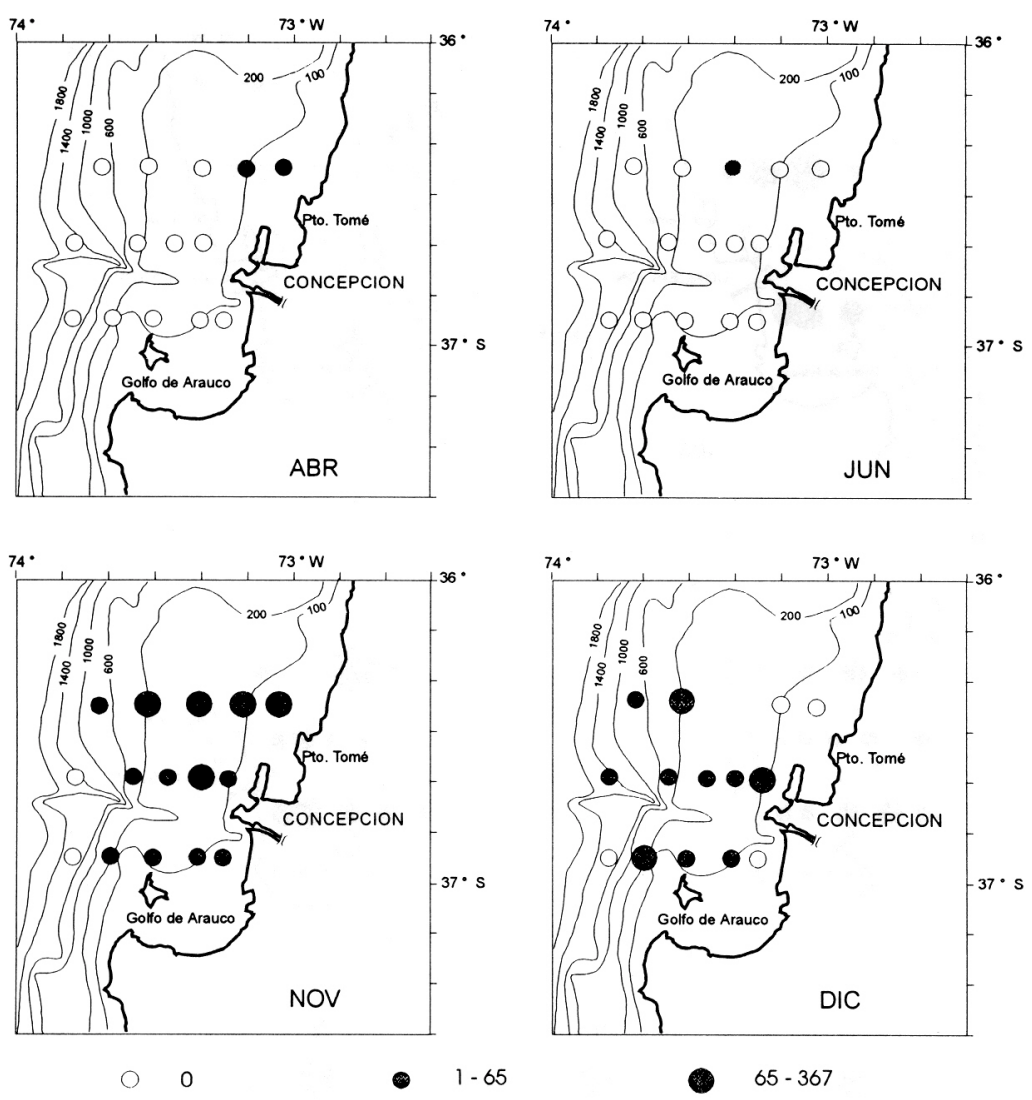

Figura 9. Distribución de larvas de langostino colorado en estado V (individuos por $1000 \mathbf{m}^{3}$ ). 
Tabla 3. Densidad media de los estados larvales de langostino por estrato de profundidad (ind./1000 $\mathrm{m}^{3}$ ). Entre paréntesis se indica el número de muestras por estrato.

\section{Estados de desarrollo}

\begin{tabular}{ccrcrrr}
\hline $\begin{array}{c}\text { Profundidad } \\
(\mathrm{m})\end{array}$ & I & II & III & IV & V & $\begin{array}{c}\text { Post- } \\
\text { larva }\end{array}$ \\
\hline $0-25(6)$ & 292 & 691 & 319 & 293 & 186 & 27 \\
$25-50(6)$ & 161 & 27 & 161 & 0 & 81 & 188 \\
$0-50(12)$ & 589 & 308 & 255 & 301 & 60 & 7 \\
$50-100(12)$ & 20 & 34 & 0 & 34 & 54 & 27
\end{tabular}

otoño, seguidos de un marcado descenso en invierno, para mostrar una notoria recuperación en primavera. La pobreza registrada en invierno, con valores comprendidos entre 36 y 344 ind./1000 m³, confirma los resultados obtenidos anteriormente
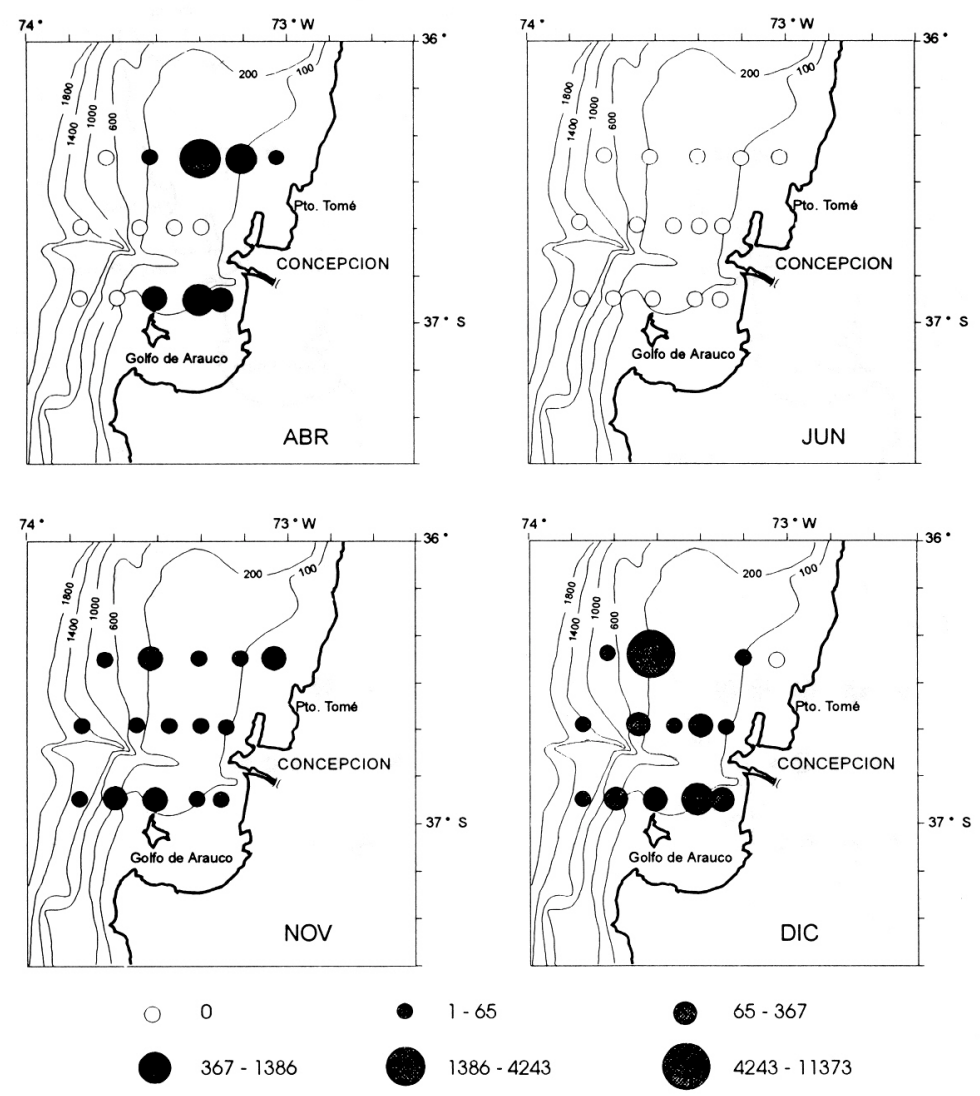

para esta misma zona por Mujica y Rojas (1980), quienes para la época de invierno determinaron valores de biomasa inferiores a 240 ind./1000 $\mathrm{m}^{3}$.

A fines de primavera, los valores de biomasa fluctuaron entre 200 y 950 ind./1000 $\mathrm{m}^{3}$, que son muy similares a los rangos de biomasa de 250 a 1250 ind./1000 $\mathrm{m}^{3}$, determinados para la región en esa misma época del año (Mujica y Rojas, 1980).

Las mayores variaciones de biomasa se produjeron por cambios importantes en la abundancia de copépodos y eufáusidos, que mostraron fuertes incrementos en primavera y en otoño. Esta mayor biomasa zooplanctónica, sostenida por poblaciones de organismos filtradores, estaría sustentada por la alta productividad primaria asociada a procesos de surgencia que ocurren frecuentemente frente a la costa de Concepción (Ahumada et al., 1991).

En general, los valores de biomasa fueron siempre más altos en aguas neríticas, con fuertes descensos en aguas del talud. Al mismo tiempo, en todos

Figura 10. Distribución de postlarvas de langostino colorado (individuos por $1000 \mathrm{~m}^{3}$ ). 


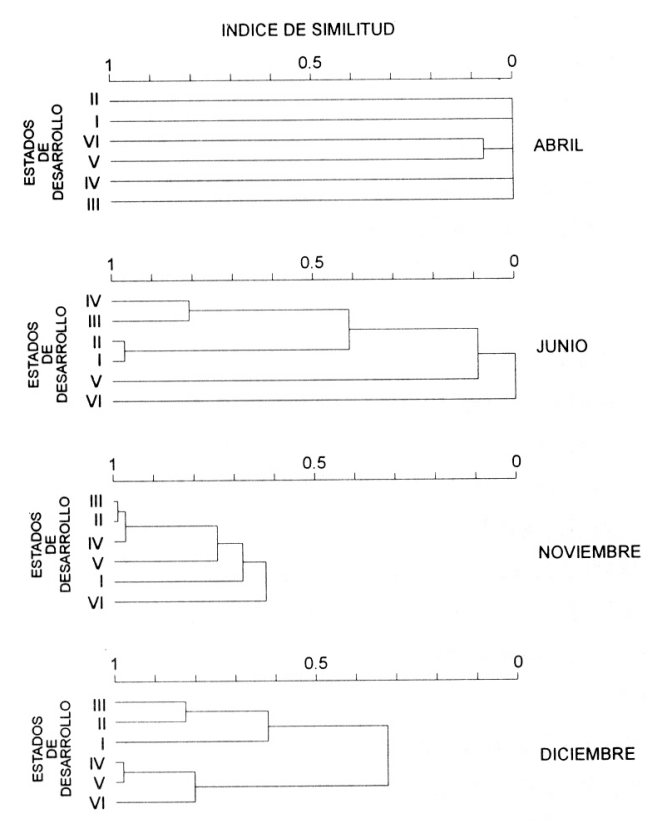

Figura 11. Dendrograma de similitud de Winer entre los estados de desarrollo del langostino colorado en los cuatro cruceros oceanográficos. los períodos del año se observaron menores valores en la sección central, situada al norte de la desembocadura del río Bío-Bío. Es probable que la menor salinidad de sus aguas pueda afectar la abundancia de zooplancton en esta región.

\section{Distribución temporal de larvas de langostino}

La distribución temporal de las larvas de langostino colorado frente a la costa de Concepción presentó un máximo anual en noviembre de 8.690 ind./1000 $\mathrm{m}^{3}$ en la estación 1 y una densidad media de 1.576 ind./1000 $\mathrm{m}^{3}$. Esta distribución estacional concuerda con los resultados encontrados por Mujica y Bahamonde (1990), quienes a fines de primavera determinaron densidades medias de 1.629 ind./1000 $\mathrm{m}^{3}$, pero con una concentración máxima mucho más elevada, de 37.644 ind./1000 $\mathrm{m}^{3}$ al interior del golfo de Arauco. Esta cantidad es muy parecida a las máximas concentraciones de hasta 42.000 ind./1000 $\mathrm{m}^{3}$, registradas para Pleuroncodes planipes al interior de Magdalena Bay, Baja California (Boyd, 1960).

El patrón de distribución estacional mostró la presencia continua de larvas de langostino colorado
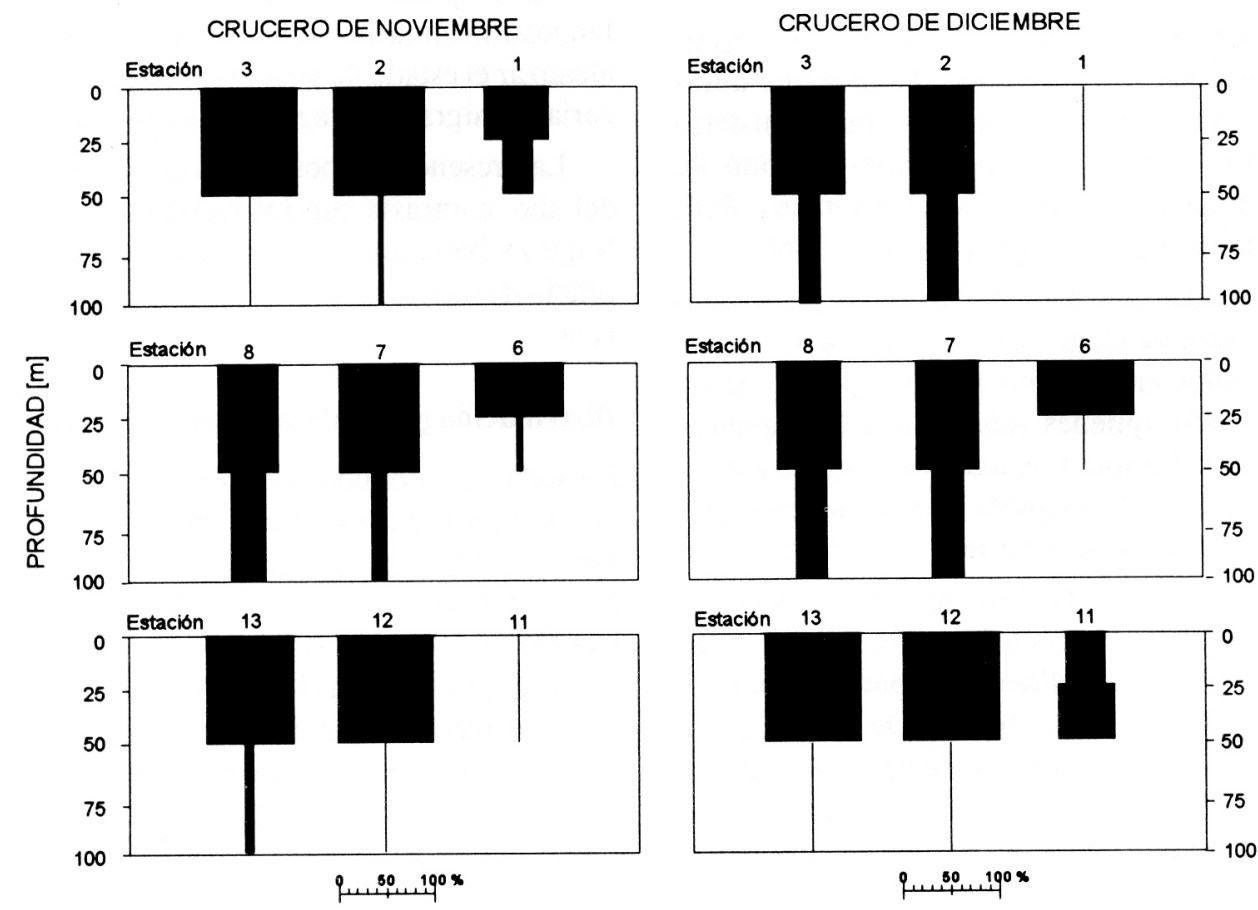

Figura 12. Distribución vertical de larvas de langostino colorado en los cruceros oceanográficos efectuados en noviembre y diciembre 1991. 
durante todo el período de estudio. Las menores cantidades de organismos se registraron en otoño e invierno, notándose un marcado incremento a mediados de primavera, seguida de un decrecimiento hacia fines de esta misma época. Las mayores densidades larvales registradas en primavera estarían asociadas a los máximos primaverales de fitoplancton (Astthorsson y Gislason, 1991). De hecho, para esta zona durante procesos de surgencia primaveral, se han registrado valores de hasta $35 \mathrm{mg}$ clorofila $a / \mathrm{m}^{3}$ (Ahumada et al., 1991).

Esta distribución estacional, caracterizada por la escasez otoñal y la abundancia primaveral, es concordante con la distribución de larvas de galateidos detectada en aguas de la costa de Valparaíso (Palma, 1976, 1980).

Las fluctuaciones de abundancia observadas frente a la costa de Concepción concuerdan con el ciclo reproductivo del langostino colorado, cuyo período de portación, de alrededor de seis meses, está centrado entre comienzos de mayo y fines de octubre, presentando la mayor incidencia de hembras ovíferas en agosto (Palma y Arana, 1990). Estos autores estiman que la hembra portaría los huevos por un lapso de 90 a 120 días, período durante el cual transcurriría el desarrollo embrionario.

Sobre esta base, se estima que el ciclo reproductivo del langostino colorado tendría una duración muy similar al de su congénere del hemisferio norte Pleuroncodes planipes, cuyo período de portación también es de seis meses, noviembre a abril, con máxima intensidad en febrero (Boyd, 1960).

La presencia continua de larvas de langostino frente a la costa de Concepción, difiere de los resultados obtenidos en esta misma zona por Bustos y Retamal (1985), quienes señalan que las hembras portan huevos durante seis meses al año, de abril a septiembre, pero indican que la liberación de los huevos se produce sólo en octubre y noviembre.

Es probable que la duración del período de portación, así como la época de mayor incidencia de hembras ovíferas, esté influenciada por las condiciones oceanográficas del ambiente. De hecho, en la bahía de Mejillones, Gutiérrez y Zúñiga (1971) determinaron que el período de portación ocurre durante todo el año, con una mayor incidencia en junio-julio, cuando casi el $100 \%$ de las hembras son portadoras.

La ausencia de larvas en los primeros estadios de desarrollo registrada en abril, indica que el período de desove aún no habria comenzado, dado que las larvas capturadas en este período correspondieron a los últimos estadios de desarrollo, zoea $\mathrm{V}$ y postlarva, que provendrían de hembras que maduraron tardíamente en la temporada anterior. Al respecto, Palma y Arana (1990) frente a la costa de Concepción, encontraron incluso algunas hembras ovíferas en diciembre.

A mediados de primavera se observaron las mayores densidades de larvas, producto del alto porcentaje de hembras ovíferas registradas en invierno (Palma y Arana, 1990). En cambio hacia fines de primavera, en diciembre, se observó un escaso número de ejemplares en estados primarios de desarrollo (zoea 1), asociado a un aumento significativo de ejemplares en estados finales de desarrollo, especialmente postlarvas.

Fagetti y Campodónico (1971) estimaron que el desarrollo larval del langostino en condiciones de laboratorio a $15^{\circ} \mathrm{C}$ demoró 55 días en alcanzar el estado de zoea $\mathrm{V}$, mientras que a $20^{\circ} \mathrm{C}$ demoró 48,3 días sin obtener la muda a zoea V Por lo tanto, dadas las características hidrológicas de la zona de Concepción, donde la temperatura superficial varía de otoño a primavera entre los 12 y $14^{\circ} \mathrm{C}$ (Ahumada y Chuecas, 1979), se puede estimar que el período larval del langostino tomaría poco más de dos meses antes de alcanzar el estado de postlarva, etapa en que comenzaría su migración a aguas más profundas.

La presencia de postlarvas en distintos períodos del año, contrasta con los resultados obtenidos por Mujica y Bahamonde (1990), quienes señalan la presencia de algunas postlarvas, sólo a fines de primavera.

\section{Distribución geográfica de larvas de langostino}

En todos los períodos del año, se observó que las larvas muestran una marcada preferencia por las aguas costeras, particularmente en la sección norte del área de estudio. Sólo a mediados de primavera, cuando se determinaron las mayores concentraciones de organismos en el plancton, las larvas se distribuyeron más homogéneamente en toda la región, incluyendo las aguas del talud continental.

En esta región, el patrón de circulación superficial muestra un flujo predominante hacia el norte, paralelo a la costa, el cual se intensifica con los vientos del sur y suroeste (Salinas, 1992). Por lo tanto, es probable que este patrón de circulación sea respon- 
sable de las mayores densidades larvarias registradas en el norte del área de estudio.

La mayor abundancia de larvas de $P$. monodon en aguas neríticas y su disminución hacia aguas oceánicas es similar al patrón de distribución determinado para su congénere de las costas de California, $P$. planipes (Longhurst, 1967). La mayor abundancia larvaria en aguas costeras responde al modelo de distribución del meroplancton de crustáceos descrito para distintas áreas geográficas (Bourdillon y Casanova, 1960; Palma, 1980; Sastry, 1983; Fuste y Gili, 1991).

Por otra parte, se observó una notoria diferencia en la distribución espacial de los estados iniciales y finales de desarrollo. En efecto, los ejemplares en estado I se capturaron más cerca de la costa, mientras que los estados más avanzados se localizaron hacia el borde de la plataforma continental, donde se determinó una alta concentración de postlarvas. Este gradiente de distribución sugiere una migración horizontal entre la costa y el talud continental en función de su estado de desarrollo de los organismos.

Estos desplazamientos podrían estar relacionados con el ciclo alimentario de las larvas, que en sus primeros estados, encuentran mayores disponibilidades de fitoplancton en aguas costeras (Asthorsson y Gislason, 1991; Ahumada et al., 1991). Afines del período de desarrollo, las postlarvas inician su migración hacia el fondo, donde encontrarian condiciones más propicias para el establecimiento de sus poblaciones juveniles de carácter bentónico. Según Gallardo et al. (1993) el asentamiento de las postlarvas estaria asociado a los fondos blandos de la plataforma continental ricos en bacterias del género Thioploca.

La distribución espacio-temporal de los distintos estados de desarrollo, muestra la correspondencia que hay entre la maduración progresiva de las hembras portadoras y la secuencia temporal entre los distintos estados de la metamorfosis larval. Todo lo cual indica que la presencia de larvas en el plancton se extendería principalmente entre junio y diciembre.

\section{Distribución vertical de larvas de langostino}

El análisis de la distribución vertical de las larvas de langostino en aguas costeras mostró una mayor concentración en los estratos superiores de la columna de agua, entre 0 y $50 \mathrm{~m}$ de profundidad. En la estación más costera de cada sección, donde se efectuó un muestreo más superficial, se registró una mayor abundancia entre 0 y 25 m (Fig. 12).

Sin embargo, se encontraron diferencias en la distribución vertical según el grado de avance en el desarrollo larval. Los primeros estados de zoea (zoea I a IV), se encontraron preferentemente en los estratos superiores de la columna de agua; en cambio el último estado de zoea muestra un incremento de individuos bajo los $50 \mathrm{~m}$, esta tendencia se acentúa en el estado de postlarva, cuyos ejemplares se capturaron preferentemente a mayor profundidad.

Estas diferencias en la distribución vertical de los distintos estados de desarrollo estarían relacionadas con el régimen alimentario de las larvas, que encuentran sus requerimientos nutritivos en las capas superficiales, situación que ha sido detectada en diversos grupos de crustáceos decápodos (Palma, 1980; Yeung y McGowan, 1991).

Además, se ha visto que las aguas costeras de la región de Concepción son afectadas frecuentemente en primavera y verano por procesos de surgencia, que causan una disminución en la concentración de oxígeno disuelto (Gallardo et al., 1993), por lo tanto es probable que esta disminución de oxígeno pueda afectar también la presencia larvaria bajo los $50 \mathrm{~m}$ de profundidad.

\section{AGRADECIMIENTOS}

Deseo expresar mis agradecimientos a los técnicos muestreadores Sres. Reinaldo Rehhoff y Noé Cáceres de la Escuela de Ciencias del Mar, quienes estuvieron a cargo de la toma de muestras de zooplancton. Al Sr. Sergio Rosales, por su participación en dos de los cruceros realizados y su colaboración en la elaboración de las figuras incluidas en el texto. A la Sra. Karim Kaiser por su colaboración en la determinación de la biomasa zooplanctónica y separación de las larvas de langostinos.

Agradezco especialmente a la Compañía Pesquera Carnanchaca S.A., que gracias a su apoyo logistico y financiero, ha hecho posible la realización del Programa de Investigación «Estudio de la dinámica de los focos de abundancia del langostino colorado (Pleuroncodes monodon) frente a la región del BíoBío» efectuado por la Escuela de Ciencias del Mar. 


\section{REFERENCIAS BIBLIOGRAFICAS}

AHUMADA, R. y L. CHUECAS. 1979. Algunas características hidrográficas de la bahía de Concepción $\left(36^{\circ} 40^{\prime} \mathrm{S} ; 7^{\circ} 02^{\prime} \mathrm{W}\right)$ y áreas adyacentes, Chile. Gayana, Miscelánea, 8: 1-56.

AHUMADA, R., P. MATRAI and N. SILVA. 1991. Phytoplankton biomass distribution and relationship to nutrient enrichment during an upwelling event off Concepcion bay Chile. Bol. Soco Biol., Concepción, 62: 7-19.

ARANCIBIA, H. y R. MELENDEZ. 1987. Alimentación de peces concurrentes en la pesquería de Pleuroncodes monodon Milne Edwards. Invest. Pesq., Santiago, 34: 113-128.

ASTTHORSSON, O. and A. GISLASON. 1991. Seasonal aboodance and distribution of Caridea larvae in Isafjord-deep, north-west Iceland. J. Plankton Res., 13(1): 91-102.

BAHAMONDE, N. y P. ZAVALA. 1981. Contenidos gástricos de Genypterus maculatus (Tschudi) y Genypterus blacodes (Schneider) capturados en Chile entre $31^{\circ}$ y $37^{\circ} \mathrm{S}$ (Teleostomi, Ophidiidae). Bol. Mus. Nac. Hist. Nat., Chile, 38: 53-59.

BAHAMONDE, N., G. HENRIQUEZ, A. ZULETA, H. BUSTOS and R. BAHAMONDE. 1986. Population dynamics and fisheries of squat lobsters, family Galatheidae, in Chile. Can. Spec. Publ. Fish. Aquat. Sci., 92: 254-268.

BOURDILLON-CASANOVA, L. 1960. Le meroplancton de golfe de Marseille: les larves de Crustacés Décapodes. Rec. Trav. Sta. Mar. Endoume, 30(18): 1-286.

BOYD, C. 1960. The larval stages of Pleuroncodes planipes Stimpson (Crustacea, Decapoda, Galatheidae). Biol. Bull. Mar. Biol. Lab., Woods Hole, 118: 17-30.

BOYD, C. and M. JOHNSON. 1963. Variations in the larval stages of a decapod crustacean, Pleuroncodes planipes Stimpson (Galatheidae). Biol. Bull. Mar. Biol. Lab., Woods Hole, 124 (3): 141-153.

BUSTOS, H. y M. RETAMAL. 1985. Estudio biológico pesquero del langostino colorado Pleuroncodes monodon H. Milne Edwards, 1837. Gayana, Zool., 49(3-4): 151-164.
BUSTOS, H., O. ARACENA, S. MORA y W. PALMA. 1982. Estudio de crecimiento y edad en el recurso langostino colorado (Pleuroncodes monodon H. Milne Edwards, 1837). Inf. Inst. Fom. Pesq., Santiago, mimeografiado, 120 pp.

F AGETTI, E. 1960. Huevos y el primer estadio larval del langostino (Cervimunida johni Porter, 1903). Rev. Chil. Hist. Nat., 55: 33-42.

FAGETTI, E. and I. CAMPODONICO. 1971. Larval development of the red crab Pleuroncodes monodon (Decapoda Anomura: Galatheidae) under laboratory conditions. Mar. Biol., 8(1): 70-81.

FRONTIER, S. 1980. Métodos de análisis rápido en muestras planctónicas. Acta Oceanogr. Pacífico, 1(1): 137-145.

FUSTE, X. and J.M. GILI. 1991. Distribution pattern of decapod larvae off the north-western lberian Peninsula coast (NE Atlantic). J. Plankton Res., 13(1): 217-228.

GALLARDO, V., I. CAÑETE, S. ENRIQUEZ, R. ROA, A. ACUÑA y M. BALTAZAR. 1993. Biología del langostino colorado Pleuroncodes monodon $\mathrm{H}$. Milne Edwards, 1837 y especies afines (Crustacea, Decapoda, Anomura, Galatheidae): Sinopsis. In: F. Faranda y O. Parra (Eds.). Elementos básicos para la gestión de los recursos vivos marinos costeros de la región del Biobío. Programa EULA, Universidad de Concepción, Monografías Científicas 2: 67-113.

GUTIERREZ, J. y O. ZUÑIGA. 1977. Pleuroncodes monodon H. Milne Edwards en la bahía de MejiHones del sur, Chile (Crustacea, Decapoda, Anomura). Rev. Biol. Mar., Valparaíso, 16(2): 161169.

HAIG, J. 1955. The Crustacean Anomura of Chile. Report of the Lunds University Chile Expedition 1848-49. Lund Univ. Arsskr. (N.F.Avd. 2), 51(12): $1-60$.

HENRIQUEZ, G. y N. BAHAMONDE. 1964. Análisis cualitativo y cuantitativo del contenido gástrico del congrio negro (Genypterus maculatus Tschudi) en pescas realizadas entre San Antonio y Constitución (1961-1962). Rev. Univ., 49: 139158.

LONGHURST, A. 1967. The pelagic phase of Pleuroncodes planipes Stimpson (Crustacea, Galatheidae) in the California Current. CalCOFI' Repts., 11: 142-154. 
MUJICA. A. y N. BAHAMONDE. 1990. Larvas de Galatheidae en plancton marino del área de Talcahuano (Crustacea, Decapoda, Anomura). Manuscrito no publicado, $15 \mathrm{pp}$.

MUJICA, A. y O. ROJAS. 1980. Estudio de reproducción, fecundidad de la sardina común (Clupea (Strangomera) bentincki) y de la anchoveta (Engraulis ringens) de la zona de Ta1cahuano. Corporación de Fomento de la Producción. Gerencia de Desarrollo. Inst. Fom. Pesq., Santiago, AP 80-3,30 pp.

PALMA, S. 1976. Meroplancton de la región de Valparaíso. Cienc. Tec. Mar, CONA 2: 99-116.

PALMA, S. 1980. Larvas de crustáceos decápodos capturadas frente a la costa de Valparaíso. Invest. Mar., Valparaíso,8(1-2): 129-144.

PALMA, S. y P. ARANA. 1990. Aspectos reproductivos del langostino colorado (Pleuroncodes monodon H. Milne Edwards, 1837) en la zona centro-sur de Chile. Estud. Doc., Univ. Católica Valparaíso, 1/ 90: 77 pp.
RETAMAL, M. 1977. Los crustáceos decápodos chilenos de importancia económica. Gayana, Zool., 39: 1-49

RETAMAL, M. 1981. Catálogo ilustrado de los crustáceos decápodos de Chile. Gayana. Zool., 44: 1110.

SAIZ, F. 1980. Experiencias en el uso de criterios de similitud en el estudio de comunidades. Arch. Biol. Med. Exp., 13: 387-402.

SALINAS, S. 1992. Corrientes sobre la plataforma continental de Talcahuano. Estud. Doc., Univ. Católica Valparaíso, 22/92: 35 pp.

SASTRY, A. 1983. Pelagic larva1 ecology and development. in: The Biology of Crustacea. Vol. 7. Behaviour and Ecology, Academic Press, London.

YEUNG, C. and M. McGOWAN. 1991. Differences in inshore-offshore and vertical distribution of phyllosoma 1arvae of Panulirus, Scyllarus and Scyllarides in the Florida Keys in May-June, 1989. Bull. Mar. Sci., 49(3): 699-714.

Recibido el 4 de mayo de 1994.

Aceptado el 9 de septiembre de 1994. 